\title{
GEOTECHNICAL ANALYSIS OF MIZUKI EMBANKMENT REMAINS
}

\author{
SHIGENORI HAYASHI ${ }^{\mathrm{i})}$ and YAN-JUN Duii)
}

\begin{abstract}
This paper presents the investigations of the historical remains of the Mizuki embankment, which was built in 664 $\mathrm{AD}$ with wide moats and a steep slope facing on one side. Considering the historical and local topographical features, it is thought that the Mizuki embankment was mainly used as a defence facility. The in-situ investigation reveals that the embankment was built using a Hanchiku (layer-compaction) method. Based on the slope stability analysis, it was found that brushwood reinforcement with a loading berm construction method proved the stability. Compacted inclined layers of soil and sand have been found in the embankment, and these layers might have been constructed to drain infiltrated water from the top of the embankment, thereby preventing the potential failure induced by heavy rainfall. The installation of the timber waterspouts across the embankment used a cut and fill method. Field investigation shows that below the wooden pillar at the west gate of Mizuki embankment, there was a compacted stiff clay layer. The seismic performance of the wooden pillar-clay system is shown to be effective by numerical analysis using program FLUSH.
\end{abstract}

Key words: brushwood reinforcement, historical remains, loading berm, seismic analysis, slope stability, timber waterspout (IGC: E6/E7/E8/E12)

\section{INTRODUCTION}

The Mizuki historical remains are located at Dazaifushi of Fukuoka Prefecture, Northern Kyushu in Japan (Fig. 1). Mizuki was built more than 1,300 years ago across the Mikasa river valley. It is one of the valuable geotechnical remains of that period. Since 1975, several large detailed surveys on the Mizuki remains have been organized and carried out under the direction of the Excavation Survey Committee of Mizuki Remains (Fukuoka-ken Board of Education, 1976; Hayashi et al., 1994; Kyushu Historical Museum, 1997). Not only archaeologists, but also geotechnical engineering researchers were involved in these surveys of the Mizuki remains. Under the guidance of the committee, exploratory trench excavations have been undertaken at the site of the remains. The excavations revealed that the remains had several special construction features, such as: a) the practice of an unique construction technique, b) the installation of a water conducting system across the embankment, and c) providing a layer of stiff clay below the timber posts at the west gate structure. The engineering significance of each of them is not well known.

This paper presents the analysis of the results of the geotechnical investigations in the following ways: (1) the construction methods adopted for the Mizuki embankment; (2) the installation method of timber waterspouts in the embankment; and (3) the seismic performance of

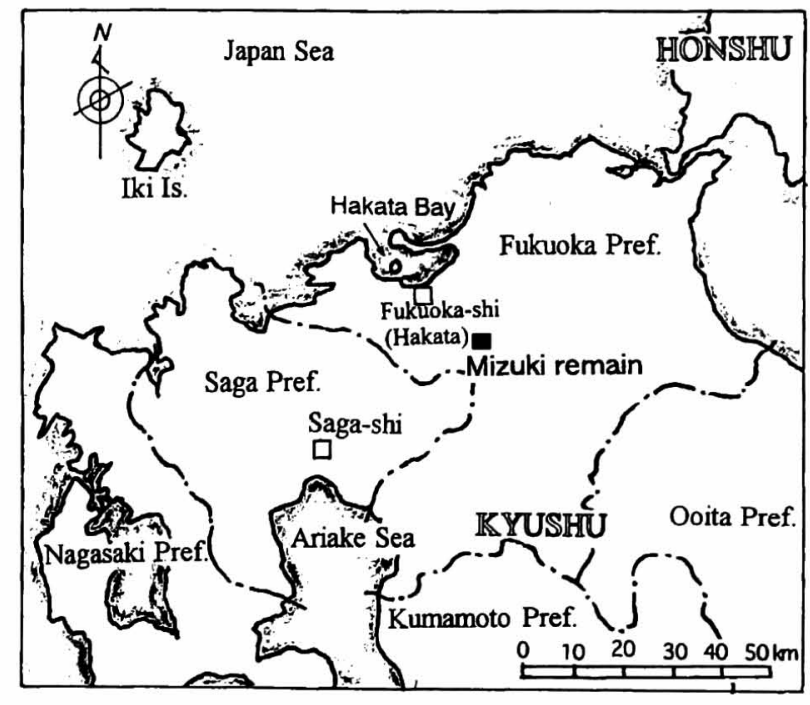

Fig. 1. Location of Mizuki remains in Northern Kyushu, Japan

the clay-timber pillar system at the west gate.

\section{CONSTRUCTION OF MIZUKI EMBANKMENT}

Topographical, Defence and Hydrological Characteristics of Mizuki Embankment

The survey, carried out in 1975 (Fukuoka-ken Board of

i) Professor, Institute of Lowland Technology, Saga University, Japan (hayashi@ilt.saga-u.ac.jp).

ii) Professor, Institute of Geotechnical Engineering, Southeast University, China (formerly Guest Associate Professor, Institute of Lowland Technology, Saga University, Japan (du@ilt.saga-u.ac.jp)).

The manuscript for this paper was received for review on August 16, 2004; approved on September 6, 2005.

Written discussions on this paper should be submitted before July 1, 2006 to the Japanese Geotechnical Society, 4-38-2, Sengoku, Bunkyo-ku, Tokyo 112-0011, Japan. Upon request the closing date may be extended one month. 


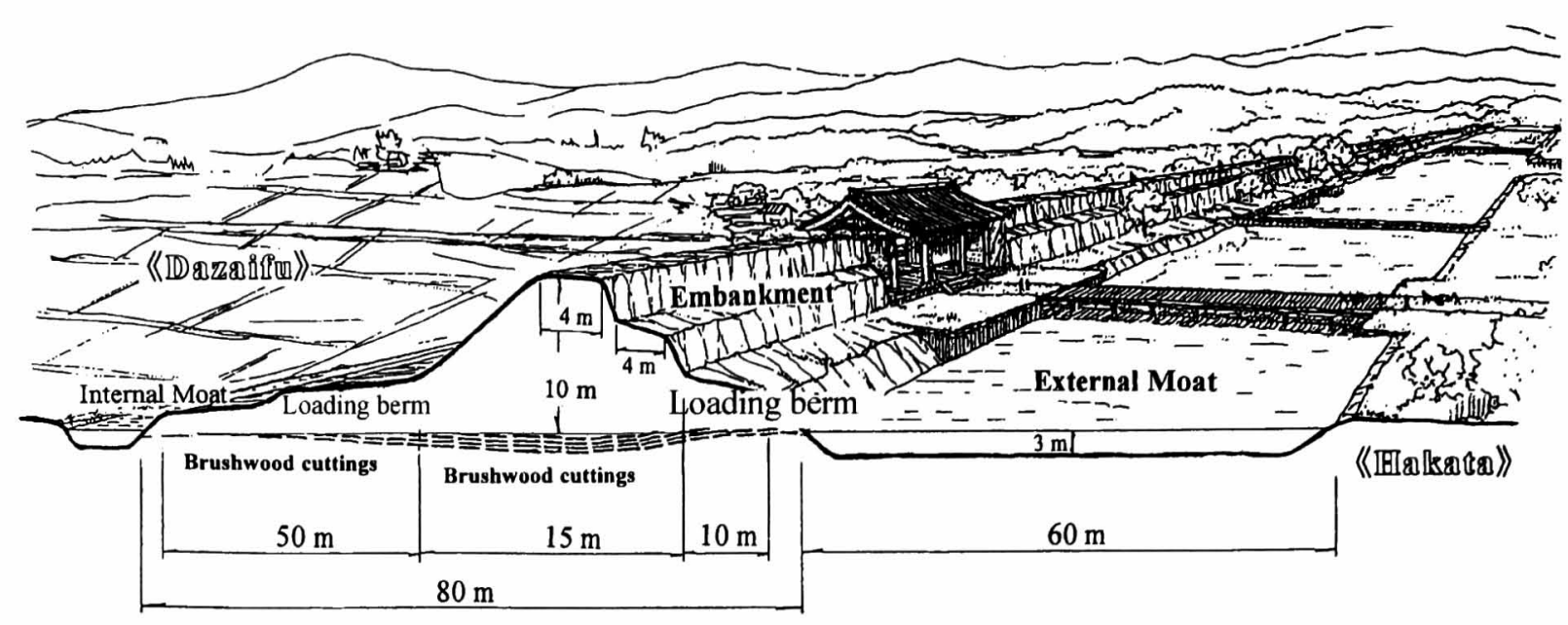

Fig. 2. Cross-section of the Mizuki embankment and moats

Education, 1976), revealed that the $1.2 \mathrm{~km}$ long Mizuki embankment was constructed approximately $10-12 \mathrm{~m}$ in height with a base width of $80 \mathrm{~m}$. The slope of the Mizuki embankment facing Hakata had an average inclination of $1: 2.2$ to $1: 2.5$, corresponding to the slope angle of about $21.8^{\circ}-24.4^{\circ}$. Facing Dazaifu, it has a very flat slope of $1: 12$ to $1: 15$, corresponding to the slope angle of about $3.8^{\circ}$ to $4.8^{\circ}$. The longitudinal profile of the remains indicated a cut in the original embankment.

To ensure the stability of the embankment with steep inclination towards Hakata, countermeasures were adopted. These construction techniques will be discussed later. The external water-filled bowl-shaped moat, close to the Hakata side, was found to have a depth of about $3 \mathrm{~m}$ and a width of approximately $60 \mathrm{~m}$, as shown in Fig. 2. At the time of building the Mizuki embankment, swords, spears, bow and arrows were the main weapons used in battle. The effective shooting range of an arrow at that time was about $60-70 \mathrm{~m}$ (Hayashi et al., 1994). Therefore, it can be inferred that this external water-filled moat with a width of about $60 \mathrm{~m}$ and an embankment of height 10 to $12 \mathrm{~m}$, with a steep slope towards Hakata, might have acted as a defense fortress against the troops entering Dazaifu. Figure 3 schematically shows the topography of the mountainous area around DazaifuMizuki in the 7th Century. From Fig. 3, it is clear that Dazaifu was surrounded by mountains and the Mizuki embankment was located on the only waterway into Dazaifu for the invading troops from Hakata (Hayashi et al., 1994). The unique topographic features of Mizuki and the surrounding area could have been the main reason why Dazaifu was chosen as the site for building the Mizuki Embankment as a defense fortress.

The field survey using Geo-radar and underground excavation (Fukuoka-ken Board of Education, 1976) has revealed the existence of timber waterspouts (sluices) at higher elevations in the eastern and western parts of the embankment. It can be inferred that these timber waterspouts were being used to fill up water into the bowl-shaped moats, for defence purposes. The locations of the east and west timber waterspouts and their

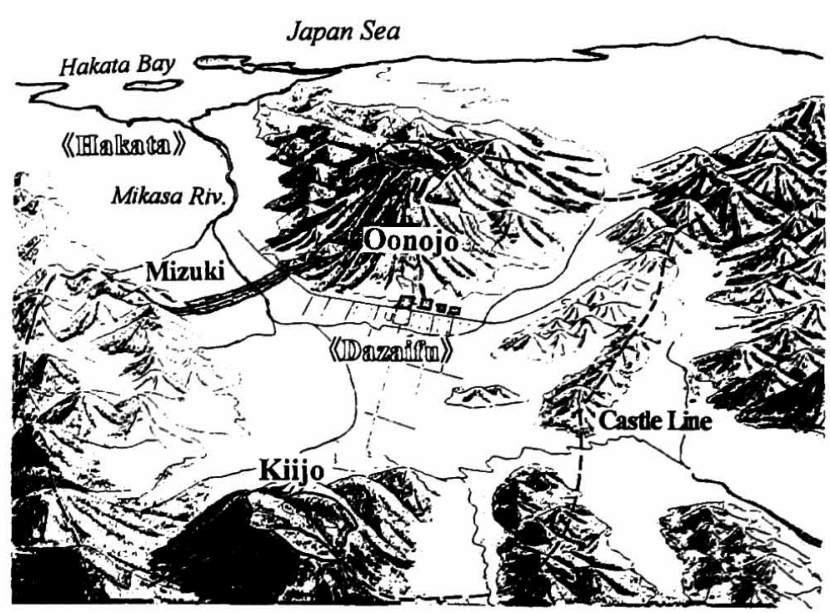

Fig. 3. Bird's-eye view of the topographic features of the mountainous area around Dazaifu (not to scale)

corresponding elevations are shown in Fig. 4. Both waterspouts had a rectangle cross-section about $120 \mathrm{~cm}$ in width, $80 \mathrm{~cm}$ in height, and consisting of four wooden planks ( see also Fig. 10). The horizontal distance between two waterspouts was about $710 \mathrm{~m}$. The installation technique used will also be discussed in a later section.

The elevation of the Mikasa riverbed was about $17.5 \mathrm{~m}$. The local government office of the Dazaifu was about $33.0 \mathrm{~m}$ (Fukuoka-ken Board of Education, 1976) at the time when the Mizuki embankment was constructed. The elevation of the Dazaifu residential area and the downtown are assumed to have been at 31.0 to $33.0 \mathrm{~m}$. The elevation of the maximum allowable water level in the Mikasa river during the heavy rainfall could not have been higher than $30.0 \mathrm{~m}$. Based on these fundamental factors, the rainfall characteristics of the Dazaifu area, and the drainage capacity of the timbered waterspout, only two waterspouts were found to be less than inadequate to carry the full, peak flood discharge of the Mikasa river (Kataoka, 1996; Toki, 1998). They concluded that at least 44 parallel waterspouts with a length of about $45 \mathrm{~m}$ would have been needed inside the em- 


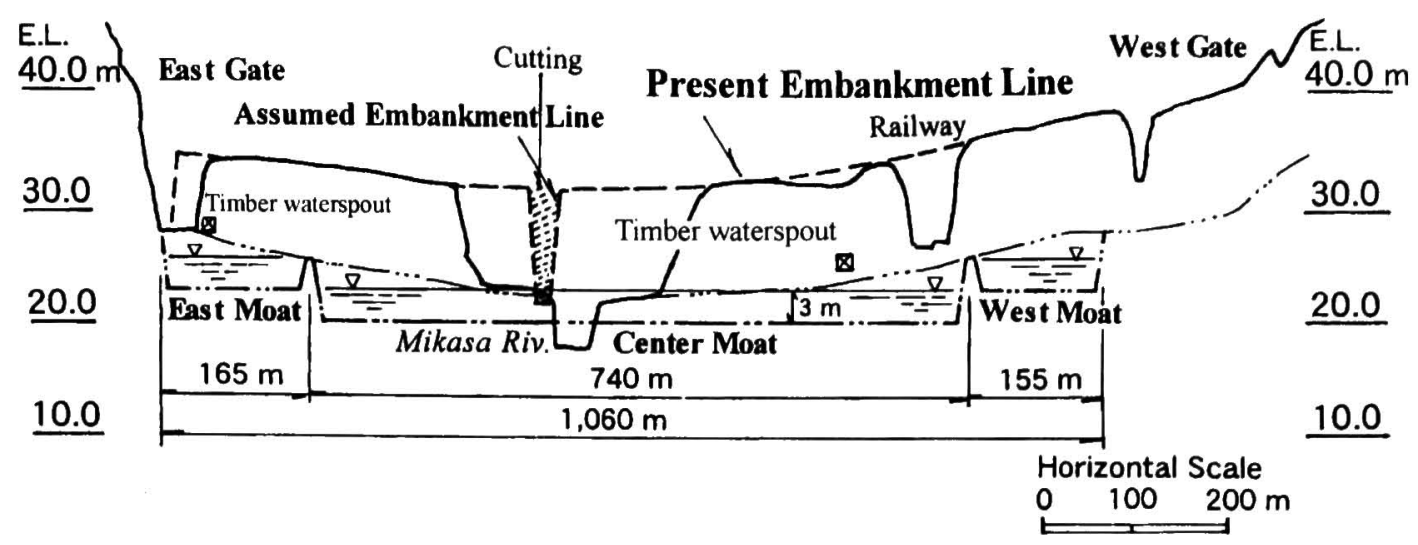

Fig. 4. Longitudinal profile of the Mizuki embankment and moats

bankment in order to keep the water level in the Mikasa river lower than the maximum allowable water level of $30.0 \mathrm{~m}$ (elevation basis). The field investigations did not reveal such a system. It is reasonable to assume that a trapezoidal cut (reversed ladder-shape) with a top width of about $38 \mathrm{~m}$ and bottom width of about $15 \mathrm{~m}$ in the initial Mizuki embankment (see Fig. 4) was required to conduct the water downstream during heavy rainfalls. The term "cut" herein refers to the removal of the embankment soils in the original Mizuki embankment. Although this method of constructing Mizuki embankment with a cut might have weakened its defense requirements, it ensured that Dazaifu did not experience flooding during heavy rainfalls. The possibility of a cut in the original Mizuki embankment itself was also indicated by Toki (1998). Based on these inferences, the original top profile of the Mizuki embankment, at the time of construction, is assumed to be shown in Fig. 4. The middle moat with a length of about $740 \mathrm{~m}$, and the east and west moats of lengths of $165 \mathrm{~m}$ and $155 \mathrm{~m}$, respectively, were thought to have existed, as shown in Fig. 4. To keep a constant water level in the moats which acted as defense facilities through out the year, there might have been large reservoirs on the Dazaifu side. They would have stored water during the rainy season, and provided water to the external moats via timber waterspouts during the dry season. Further investigation needs to be carried out to prove this theory.

\section{Construction Techniques of Mizuki Embankment}

The trench excavation of the Mizuki embankment carried out in 1993 reveals that the Mizuki embankment was constructed using the Hanchiku (layer-compaction) method, with mallets used for compacting the soils (Dazaifu-shi Board of Education, 1994). Field investigation shows that the average water content and the average density of the compacted soils are in the range of $21-23 \%$ and $17.6 \mathrm{kN} / \mathrm{m}^{3}$ respectively, as shown in Fig. 8(a) presented later in this paper. The grain size distribution tests showed that the effective grain size $D_{10}$ and the mean grain size $D_{50}$ of the soil were about $0.05 \mathrm{~mm}$ and $0.8 \mathrm{~mm}$, respectively. The laboratory compaction test with a compact energy of about $550 \mathrm{~kJ} / \mathrm{m}^{3}$ for the sampled

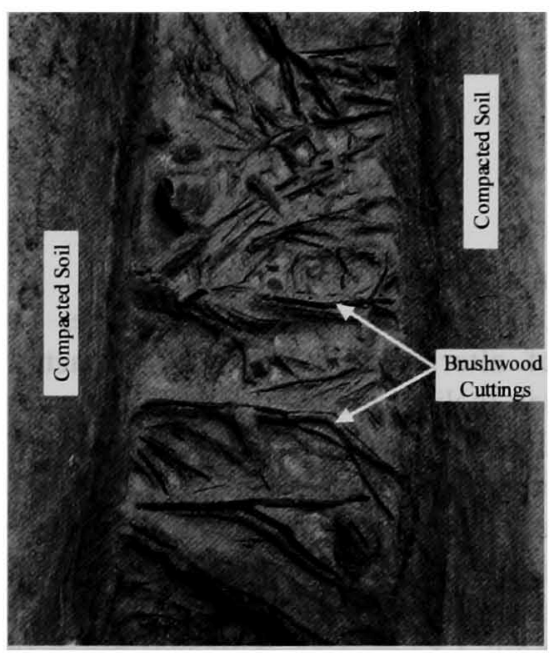

Fig. 5. Shikisoda remains from the trench-excavation survey in 1993

in-situ embankment soils shows that the optimum water content and the maximum dry density of the embankment soils are about $14 \%$ and $18.1 \mathrm{kN} / \mathrm{m}^{3}$, respectively (Motoyama, 1995). It was also found that Mizuki embankment was reinforced by brushwood cuttings along the base of the embankment as shown in Fig. 2 . At the center of the embankment base, the brushwood cuttings were placed in 3 layers, with 1 to 2 layers at positions away from the center line (Fig. 2). This reinforcement method is titled the "Shikisoda Method", which is very much similar to the current soft ground improvement technique, such as earth reinforcement using geogrid/geonet. The remains of the Shikisoda Method from the trench-excavation survey of 1993 are shown in Fig. 5.

The Mizuki embankment had been excavated during the construction of the National Railway in 1913. The brushwood cuttings had been dug out during this construction process as described by Kuoita (1915). According to those records, it was found that even after 1,250 years, the leaves of the brushwood were still a bright enough color of green to identify the tree. It would appear that some innovative technique was used which ensured the high durability of these natural reinforce- 


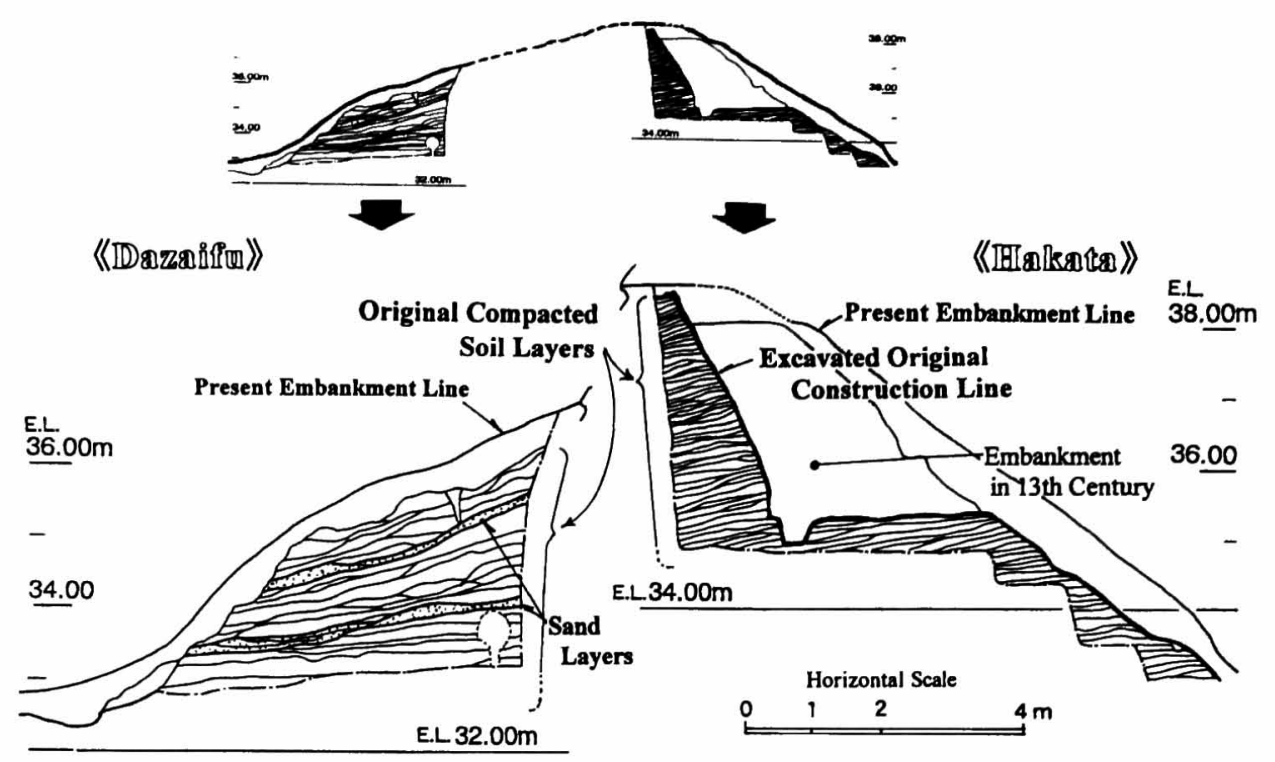

Fig. 6. Inclined compacted layers in the embankment

ments (Yamada, 1997).

Observation of the excavated trenches revealed the presence of alternating layers of compacted soils and sands, which incline downwards and towards Dazaifu as shown in Fig. 6 (Kyushu Historical Museum, 1997). It was further revealed that inclined compacted sand layers were spaced, on average, every $1.3 \mathrm{~m}$. The soil in the embankment towards Hakata had been compacted in layers with a thickness of $7-10 \mathrm{~cm}$, and inclined at an angle of about $3.8^{\circ}$ to $4.8^{\circ}$. This was much thinner than the layers in the embankment towards the Dazaifu side.

The relative properties of the compacted inclined soil layers used in the construction of the Mizuki embankment are summarized in Fig. 7(a). The soils close to the Dazaifu side have greater permeability, lower density and thicker layers relative to those on the Hakata side. Also there are compacted inclined sand layers close to the Dazaifu side, which were designed to drain the infiltrated rainwater out of the embankment during rainfalls (Fig. 7(b)). However, on the Hakata side, such compacted sand layers were not found. Such a design of density, permeability, thickness of embankment soils and the presence of compacted inclined sand layers are thought to have two geotechnical functions: 1) to ensure that the seepage line of the rainwater in the embankment slope towards the Dazaifu was not developed in the rainy season. It is known that the rainfall, especially the heavy rainfall, will cause seepage of rainwater in the embankment, therefore inducing potentially progressive failure of the embankment slope (Nishigaki and Tohari, 2000; Fredlund, 1987). Figure 7(a) shows that the soils in the embankment on the Hakata side are compacted at relatively higher density and lower permeability. As a result, it is thought that seepage of rainwater in the embankment on the Hakata side would not be developed or would be much less considerable. The rainfall-induced potential failure of the embankment on the Hakata side

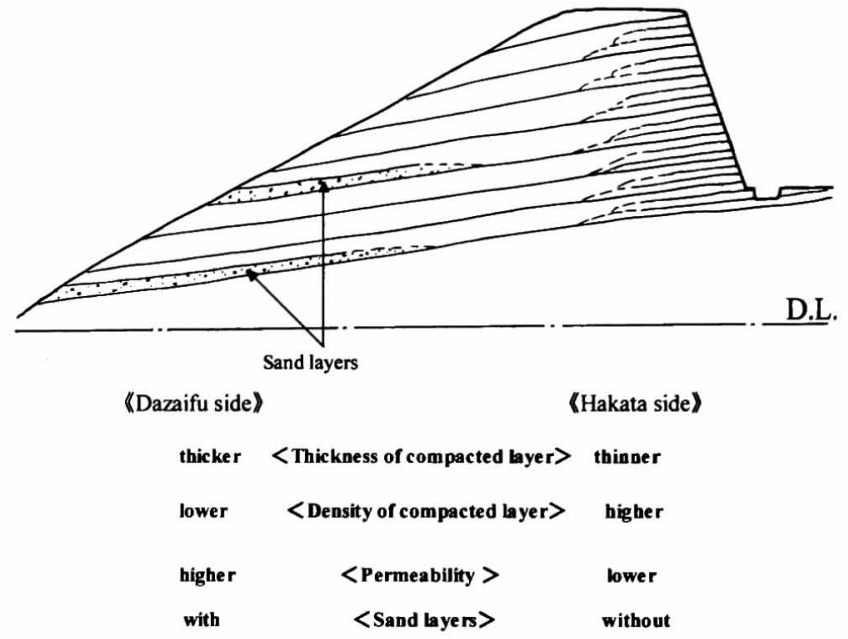

Fig. 7(a). Properties of the compacted soils in the Mizuki embankment

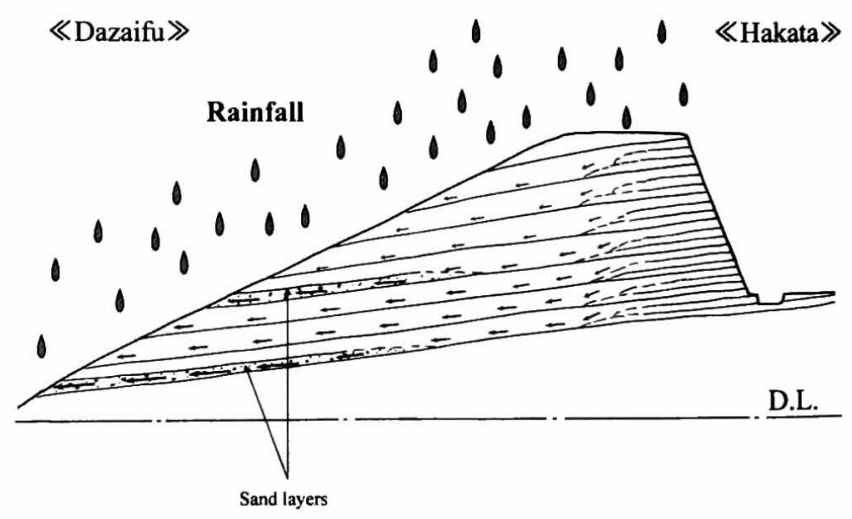

Fig. 7(b). Inclined sand layers for draining the infiltrated rain water 


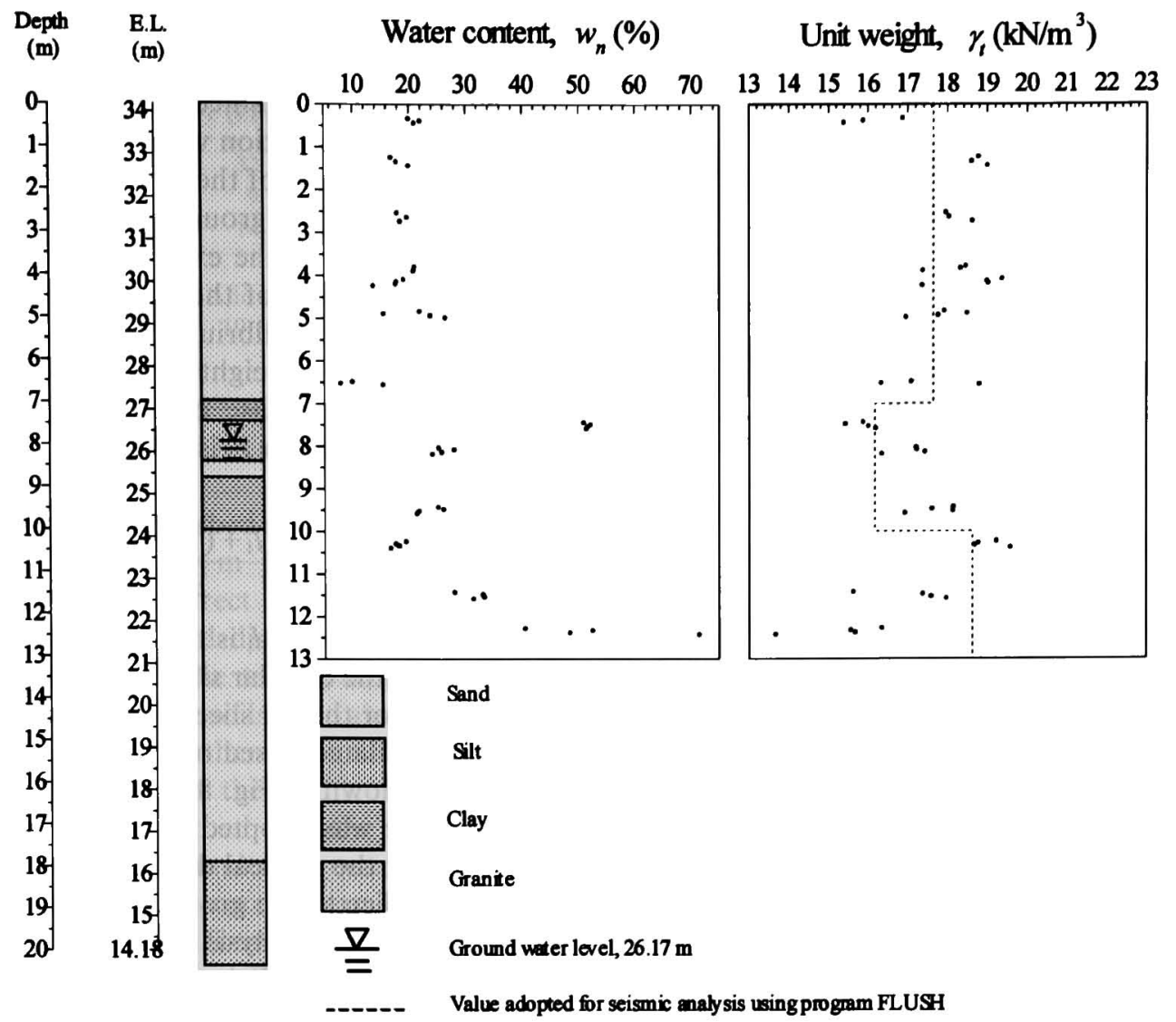

(a) water content and unit weight

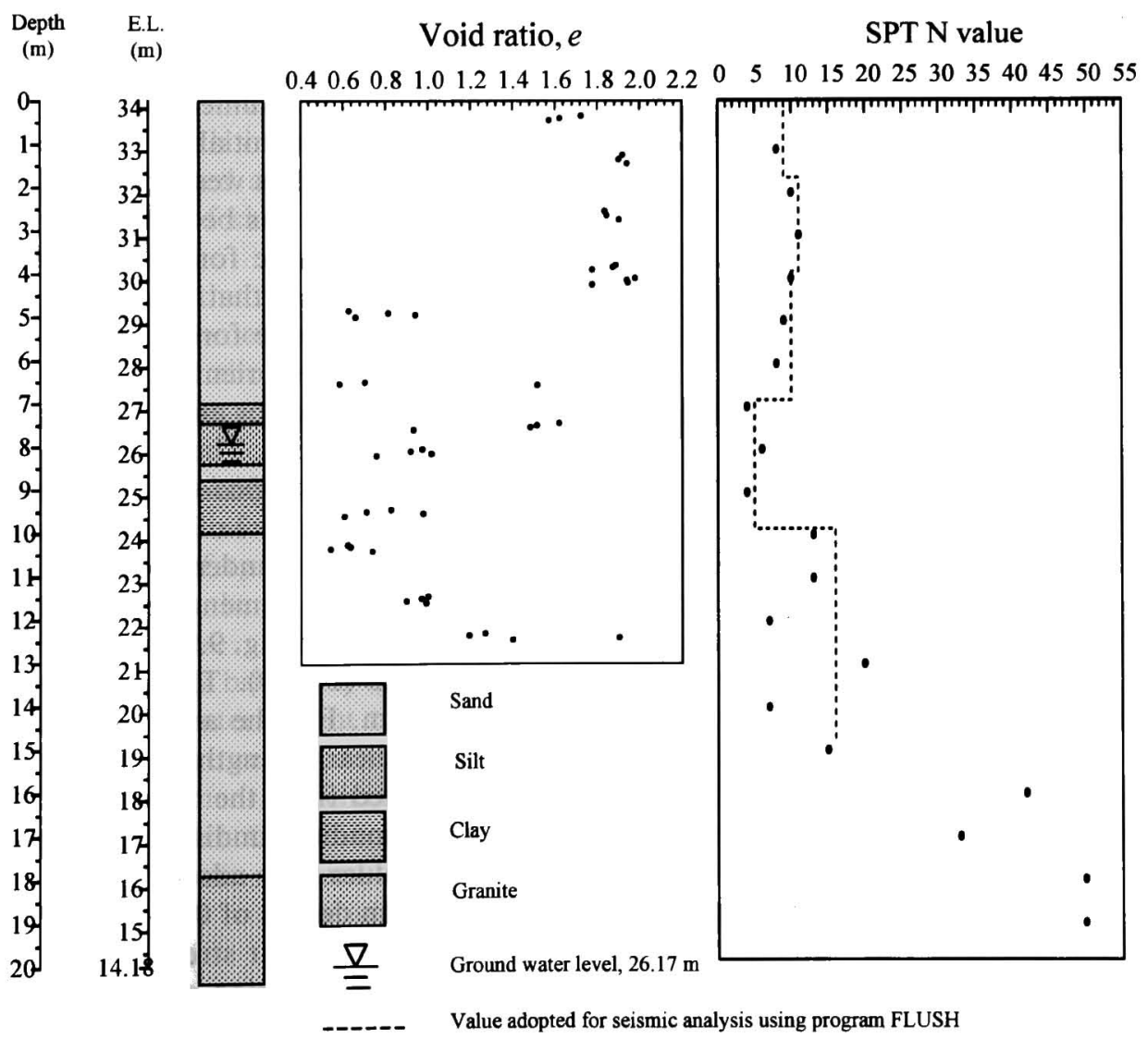

(b) void ratio and SPT $N$ value

Fig. 8. Geo-technical properties of the soils in the Mizuki embankment 


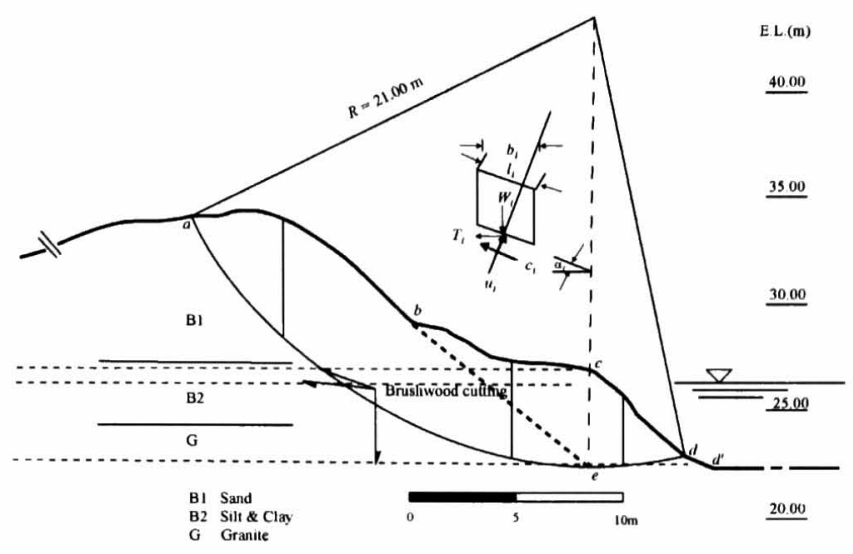

Fig. 9. Model for stability analysis of Mizuki embankment

was then suppressed; and 2) to ensure the rainwater infiltrated in the embankment on the Dazaifu side was drained in the rainy season. From Fig. 7(a), it can be seen that there are inclined compacted sand layers in the embankment on the Dazaifu side. With the presence of these sand layers, it is thought that the infiltrated rainwater could be effectively drained (Fig. 7(b)), and thereby ensuring the dryness of the overlying and underlying compacted soil layers, even under the heavy rainfall conditions. The dryness of the soils ensured the sufficient matric suction and thereby the strength of the soils. As a result, the embankment had been free from rainfallinduced failures. A further numerical analysis regarding the seepage properties of rainfall in the embankment on the Dazaifu side would be much helpful for understanding the aforementioned mechanisms.

\section{Stability Analysis of Mizuki Embankment}

In 1996, soil boring was undertaken at the top of the Mizuki embankment. The bore-log records show that the soils of the embankment can be classified into two groups: a) 0-7 m (depth), yellowish brown sand, which is titled the "Masado" (decomposed granite), and b) 7-10 $\mathrm{m}$, mainly composed of light grayish clay and silt. The original ground is below $10 \mathrm{~m}$, and is mainly composed of alluvial sand and weathered granite (Fig. 8). The so called Masado might have been brought from the pits in the surrounding mountains and the silt and clay underlying the Masado might have been brought from the local farming land. The average SPT $N$ value of the Masado layer is 9 and can be classified as loose sand, whereas the average SPT $N$ value of the silt and clay layer is 5 and its consistency can be classified as medium.

At depths of $7.34 \mathrm{~m}, 7.94 \mathrm{~m}$ and $11.64 \mathrm{~m}$, there are three layers of brushwood cuttings of diameter $0.01 \sim 0.02 \mathrm{~m}$ with an average horizontal spacing of $0.1 \mathrm{~m}$ between each wood.

The stability of Mizuki embankment was analyzed using Fellenius method. The potential sliding mass was divided into several slices as shown in Fig. 9. The height of the slope is almost $12 \mathrm{~m}$. The radius of the critical circular slip surface is $21.00 \mathrm{~m}$. The ground water level at the time of boring was at a depth of $8.00 \mathrm{~m}$. The original ground water level could have been higher than the current ground level since the brushwood cuttings still remain in good condition without obvious decay (Fig. 5). For stability analysis of the embankment, no attempt was made to adjust the ground water level, as it seemed impossible to assess the exact ground water level at the time of construction of the embankment.

Each slice is in equilibrium under the forces acting on it (Fig. 9); viz. its own weight $W_{\mathrm{i}}$, pore water pressure $u_{\mathrm{i}}$ and cohesion $c_{\mathrm{i}}$. In the case of analysis without reinforcement, the safety factor $F_{\mathrm{s}}$ is calculated using the following equation:

$$
F_{\mathrm{s}}=\frac{M_{\mathrm{R} 0}}{M_{\mathrm{D} 0}}=\frac{\sum R\left(c_{\mathrm{i}} l_{\mathrm{i}}+\left(W_{\mathrm{i}}-u_{\mathrm{i}} b_{\mathrm{i}}\right) \cos \alpha_{\mathrm{i}} \tan \phi\right)}{\sum R W_{\mathrm{i}} \sin \alpha_{\mathrm{i}}}
$$

where $b_{\mathrm{i}}$ is the width, $l_{\mathrm{i}}$ is the length of slip surface, $R$ is the radius of the circular sliding arc and $\alpha_{\mathrm{i}}$ is the angle of slip surface for the $i$ th slice. The own weight of the slice, $W_{\mathrm{i}}$, was calculated based on the unit weight and ground water level shown in Fig. 8. The pore water pressure, $u_{i}$, for each slice was adopted as the value of water density multiplied by the vertical distance from the center of the base of the slice to the ground water level.

In the case of analysis with the brushwood cutting reinforcements, Eq. (2) is used:

$$
F_{\mathrm{s}}=\frac{M_{\mathrm{RT}}}{M_{\mathrm{DT}}}=\frac{M_{\mathrm{R} 0}+\sum R\left(T_{\mathrm{i}} \cos \alpha_{\mathrm{i}}+T_{\mathrm{i}} \sin \alpha_{\mathrm{i}} \tan \phi\right)}{M_{\mathrm{D} 0}}
$$

where $T_{\mathrm{i}}$ is the allowable tensile strength of brushwood reinforcement acting on the $i$ th slice. In this study, the tension force was assumed to be horizontal mainly due to two reasons: 1) the initial install orientation of the brushwood reinforcements were thought to be horizontal; and 2) although there has been debate on the orientation of the mobilized tensile force in the reinforcement, Rowe and $\mathrm{Li} \mathrm{(2002)}$ stated that there is strong evidence that the reinforcement tensile force should be taken to act in its original horizontal orientation, when the limit equilibrium method is used for analyzing the stability of the reinforced embankment. The assumed shapes of the sliding soil mass were the abcdea part and abea part under the condition with 3 layers of brushwood reinforcements and loading berm, and under the condition with 3 layers of brushwood reinforcements without loading berm, respectively, as shown in Fig. 9. The points $a, e$ and $d$ are on the sliding circle (Fig. 9). The part $b c d d$ 'eb represents the loading berm. For the analysis, 26 slices were adopted. The peak shear strength parameters of each soil layer were obtained from the direct undrained shear tests for the corresponding undisturbed samples and then the averaged values were adopted for the analysis of the soil samples from depths of 0-7 $\mathrm{m}, 7-10 \mathrm{~m}$, and 10-11.68 m. These averaged shear strength parameters were reduced to $65 \%$ in consideration of the aging effect (cementation effect) on the shear strength (Hayashi, 2004). This effect of aging on the soil shear strength was evaluated using the laboratory direct undrained shear tests (Motoyama, 1995). In the investigation carried out by Motoyama 
Table 1. The parameters of three layers of soil used for the stability analysis

\begin{tabular}{lcccc}
\hline Layer & Depth $(\mathrm{m})$ & $c(\mathrm{kPa})$ & $\phi\left(^{\circ}\right)$ & $R(\mathrm{~m})$ \\
\hline B-1 & $0-7.00$ & 32 & 10 & \\
B-2 & $7.00-10.00$ & 9 & 5 & 21.00 \\
G & $10.00-11.68$ & 14 & 5 & \\
\hline Brushwood & 7.34 & & Allowable tensile strength $T$ is \\
& 7.94 & $19.6 \mathrm{kN} / \mathrm{m}$ (Ohhama, 1974) \\
\hline
\end{tabular}

B-1: Sand, B-2: Silt and clay, G: Decomposed granite

(1995), undisturbed and disturbed soils were sampled at a depth of about $5.05 \mathrm{~m}-5.34 \mathrm{~m}$ from the top of the embankment. Laboratory direct undrained shear tests for both undisturbed soil and disturbed soil conditions were performed. Although the testing condition, water content and dry density of the soils were almost the same, the test results revealed that there was difference in the peak shear strength between the undisturbed soil and disturbed soil. For the disturbed soil, the specimen was made by compacting the soil under the condition that the dry density and water content were the same with those of the undisturbed soil. It was found that the peak shear strength of the undisturbed sample was about $62 \mathrm{kPa}$. The peak shear strength of the compacted disturbed soil was about $40 \mathrm{kPa}$, which was almost $65 \%$ of that of the undisturbed soil. This difference was thought mainly due to the cementation of the soils during the long term after the field compaction. The shear strength parameters are summarized in Table 1.

The allowable tensile strength of brushwood cutting reinforced system, $T_{i}$, is adopted as $20 \mathrm{kN} / \mathrm{m}$ per layer based on the tensile strength of single brushwood reinforcement (Ohhama, 1974).

The results showed that in the case of analysis with neither loading berm nor brushwood reinforcements, the minimum safety factor was just about 1.00 , while for the case with a loading berm as the counter-weight fill, the minimum safety factor increased to 1.11 . Further analysis revealed that for the embankment reinforced with 3 layers of brushwood cutting reinforcements and with a loading berm, the minimum safety factor increased to a value more than 1.20 , which is the specified value in the modern design of embankments.

The above discussions clearly bring out that the loading berm in the form of a counter-weight together with brushwood reinforcements were required to ensure the stability of the Mizuki embankment, which is comparable to the modern practice of construction of embankments. Further these measures could have reduced the construction period.

\section{INSTALLATION OF TIMBER WATERSPOUTS}

The west timber waterspout was dug out during the 17th Survey on Mizuki remains in 1990. The waterspout as already mentioned had a rectangle shape in cross-

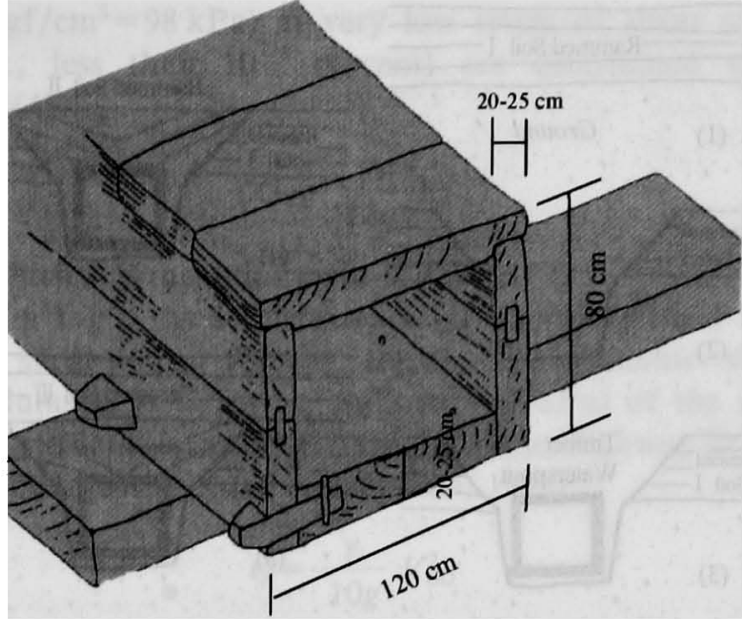

Fig. 10(a). A sketch of the cross section of the timber waterspout

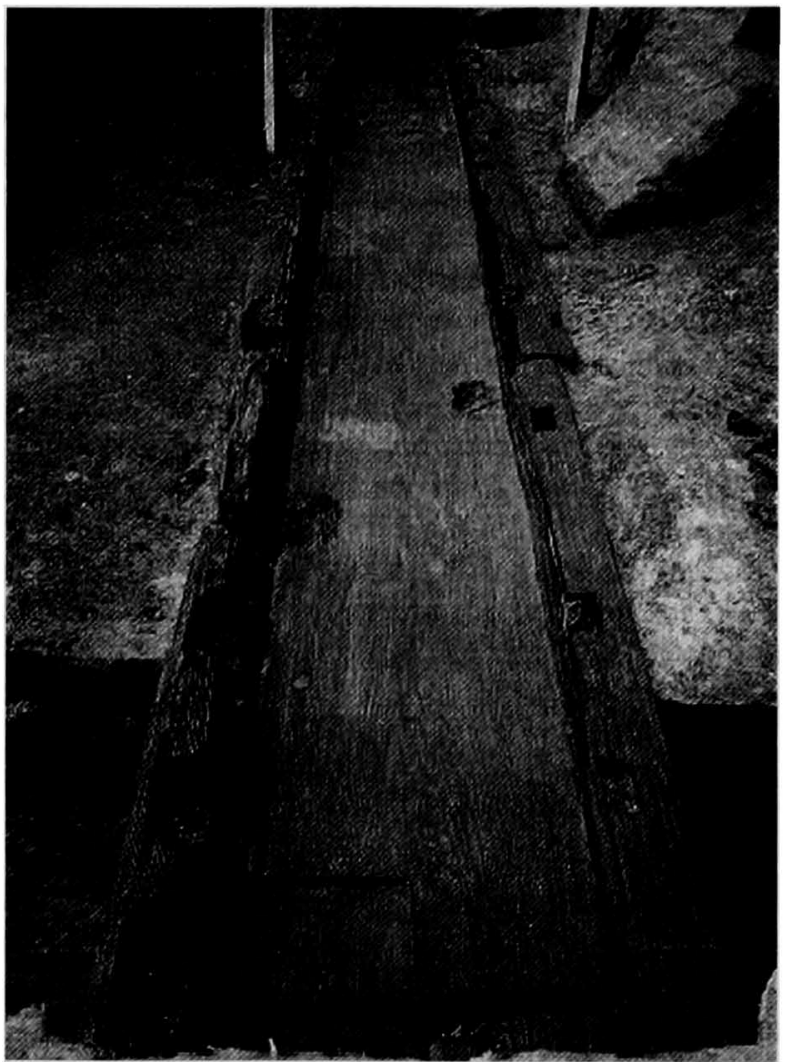

Fig. 10(b). A picture showing the timber waterspout that was dug out

section with about $120 \mathrm{~cm}$ in width, $80 \mathrm{~cm}$ in height and composed of four wooden planks (Figs. 10(a) and 10(b)). The thickness of each plank is approximately $20-25 \mathrm{~cm}$. The investigations have shown that the soil surrounding the west timber waterspout had been of rammed earth being different from the ground soil. This indicates that the construction was made with cut and fill technique. Based on the field observations, the probable construction sequence followed in the installation of waterspouts in the Mizuki embankment can be inferred as: (1) embankment constructed to certain height above the ground with rammed earth (rammed soil-I); (2) the 

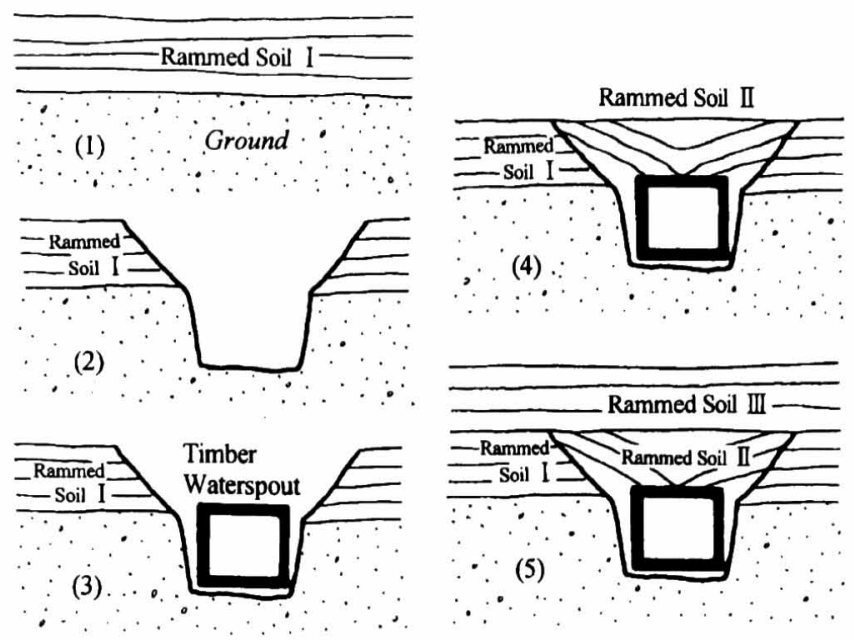

Fig. 11. Different stages of construction of waterspouts

rammed soil-I and ground excavated to the required depth; (3) timber waterspout installed in the excavated trench; (4) trench back-filled by rammed earth (rammed soil-II), and (5) further embankment raised with rammed earth (rammed soil-III). These features are illustrated in Fig. 11. This type of construction sequence is also similar to the modern flexible conduit installations. It is interesting to estimate the limit excavation depth $H c$ associated with the construction sequence (2). A rough estimation of $\mathrm{Hc}$ can be obtained using the method proposed by Taylor (1937) by assuming the properties of the compacted soil: the density, the cohesion and the angle of shear resistance of the compacted soil, and the excavated slope angle. With these assumed parameters, one can easily estimate the value of $\mathrm{Hc}$ from the design chart proposed by Taylor (1937).

\section{SEISMIC PERFORMANCE OF CLAY-WOODEN PILLAR SYSTEM}

The survey on the west gate of Mizuki embankment was conducted in 1996, and a wooden pillar supporting the west gate supper structure was dug-up. It is thought that the west gate was used as the stately pass-door with roof for the ancient local people at that time. The wooden pillars were used for supporting the upper roof. For this reason, the pillar is assumed as the rigid frame pier, and was modeled as the beam element in the seismic numerical analysis presented later in this paper. The wooden pillar was found to have been placed over a stiff gray clay layer filled in a pit made in the hard ground as shown in Fig. 12. In Fig. 12, the shaded part in the pit surrounded by the rammed soil shows the remains of the pillar. The bedding length of the pillar in the stiff clay layer was found to be about $0.4 \mathrm{~m}$. The wood is Japanese cedar. Another similar pit was also found. However, the remained pillar was not found in this pit. The horizontal distance between the two pits along the direction of the Mizuki embankment length was about $4 \mathrm{~m}$. Therefore it is thought that there would be at least 2 wooden pillars

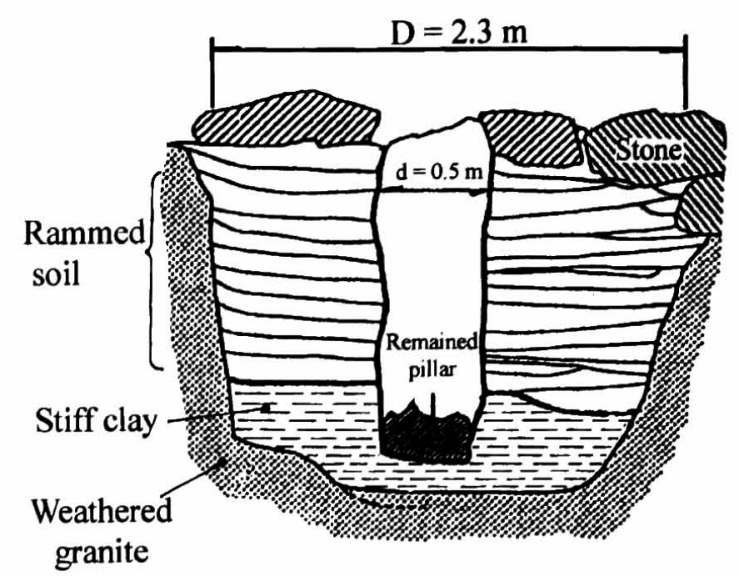

Fig. 12. A sketch of timber pillar installed inside clay

Table 2. Some geotechnical properties of the clay underlying the pillar

\begin{tabular}{lc}
\hline \multicolumn{1}{c}{ Property } & Value \\
\hline Specific gravity, $G_{\mathrm{s}}$ & 2.639 \\
Liquid limit, $w_{\mathrm{L}}(\%)$ & 57 \\
Plastic limit, $w_{\mathrm{p}}(\%)$ & 38 \\
Grain size distribution $(\%)$ & \\
Clay fraction $(<0.0002 \mathrm{~mm})$ & 72.0 \\
Silt fraction $(0.002 \mathrm{~mm} \sim 0.075 \mathrm{~mm})$ & 14.0 \\
Sand fraction $(0.075 \mathrm{~mm} \sim 2 \mathrm{~mm})$ & 3.0 \\
Gravel fraction $(>2 \mathrm{~mm})$ & 11.0 \\
Yield stress $(\mathrm{kPa})^{\mathrm{a})}$ & 900 \\
Young's modulus $(\mathrm{MPa})^{\mathrm{b})}$ & 6.9 \\
Poisson's ratio, $v^{\mathrm{b})}$ & 0.40 \\
Elastic shear modulus $(\mathrm{MPa})^{\mathrm{b})}$ & 2.55 \\
\hline
\end{tabular}

a) determined from oedometer test.

b) determined from triaxial test.

with the horizontal distance of about $4 \mathrm{~m}$ along the Mizuki embankment length. For simplicity, in the numerical seismic analysis presented later in this paper, two wooden pillars were assumed. Some geotechnical properties of the stiff clay are summarized in Table 2. The clay was found to have the yield stress of about $900 \mathrm{kPa}$, which is almost five to six times larger than that of the overburden pressure $(150-200 \mathrm{kPa})$ induced by the weight of the pillar and the supper structure. Therefore, it is clear that the clay had been overconsolidated to an OCR of about 5 to 6 . The overconsolidation partly might have been due to the cementation effect over such a long period. However, credit must be given for having achieved such a high degree of overconsolidation.

The placement of such stiff clay below the pillar may have been based on three possible decisions; (1) to suppress the decay of the lower part of the pillar; (2) to distribute the overburden loads effectively; and (3) to resist the effects of earthquakes on the superstructure. The aspect (3) seems to be supported by the following historical record. According to Nihon Shoki, in 679 there was a big earthquake at the Chikugo Plain of the Northern Kyushu region. The earthquake, titled Chikushi earthquake, was caused by the Minou active fault covering Kurume-Shi, Tanushimaru-Machi, Yoshii- 
Machi and Umaha-Machi, with a length of about $20 \mathrm{~km}$ and direction of $E W$ (Matsumura, 1996). The magnitude scale of the earthquake was about 7.1 (Matsumura, 1996). According to Nihon Shoki, this earthquake caused huge damage to the surrounding residents and houses. However, the west gate fortunately survived from this earthquake (Matsumura, 1996). This finding may imply that the west gate may have been constructed with the earthquake-resisting technique, the presence of the stiff clay. The intention of placing the stiff clay below the pillar is considered to be similar to the modern earthquake-resisting technique in which the multi-layered rubber is placed between the superstructure and foundation (Hayashi, 2003). To verify this assumption, the seismic numerical analysis was performed using the program FLUSH (Lysmer et al., 1975). The input parameters of the wooden pillar and underlying the clay for the numerical analysis are summarized in Table 3(a). Young's modulus $E$, and Poisson's ratio $v$, of the clay were measured from the triaxial test and the shear modulus was computed using Eq. (3):

$$
G=\frac{E}{2(1+v)}
$$

Young's modulus and Poisson's ratio of the wooden pillar adopted in the analysis are $800 \mathrm{MPa}$ and 0.25 , respectively (Ohhama, 1974). The initial shear modulus of the wooden pillar is calculated as $320 \mathrm{MPa}$ using Eq. (3).

For the numerical analysis of the ground-pillar system, the adopted soil layers and mesh are shown in Fig. 13. The soil layers are divided based on the soil properties shown in Fig. 8. The input parameters of the soil layers for the analysis are summarized in Table 3(b). All of the parameters listed in Table 3 are in SI unit. For each layer of the ground, the initial shear modulus $G_{0}\left(\mathrm{kgf} / \mathrm{cm}^{2}\right)$

Table 3(a). Input parameters of wooden-pillar and underlying clay for earthquake response analysis using program FLUSH

\begin{tabular}{lcccc}
\hline Materials & $\begin{array}{l}\text { Unit weight } \\
\gamma_{1}\left(\mathrm{kN} / \mathrm{m}^{3}\right)\end{array}$ & $\begin{array}{c}\text { Poisson's } \\
\text { ratio } v\end{array}$ & $\begin{array}{c}\text { Initial shear } \\
\text { modulus } \\
G_{0}(\mathrm{MPa})\end{array}$ & $\begin{array}{c}\text { Damping } \\
\text { ratio }\end{array}$ \\
\hline $\begin{array}{l}\text { Wooden } \\
\text { pillar }\end{array}$ & 14.7 & 0.25 & 320 & 0.05 \\
\hline Clay & 16.2 & 0.40 & 6.9 & 0.065 \\
\hline
\end{tabular}

$\left(1 \mathrm{kgf} / \mathrm{cm}^{2}=98 \mathrm{kPa}\right)$ at very low levels of shear strain (e.g., less than $10^{-3}$ percent) are determined using Eq. (4):

$$
G_{0}=\frac{\gamma_{\mathrm{t}}}{10 g} V_{\mathrm{s}}^{2}
$$

in which $\gamma_{\mathrm{t}}$ is the unit weight of soil $\left(\mathrm{tf} / \mathrm{m}^{3}\right)\left(1 \mathrm{tf} / \mathrm{m}^{3}=9.8\right.$ $\left.\mathrm{kN} / \mathrm{m}^{3}\right), g$ is the acceleration of gravity $\left(\mathrm{m} / \mathrm{s}^{2}\right)$ and $V_{\mathrm{s}}$ is the shear wave velocity $(\mathrm{m} / \mathrm{s})$. The dynamic shear modulus $G\left(\mathrm{kgf} / \mathrm{cm}^{2}\right)\left(1 \mathrm{kgf} / \mathrm{cm}^{2}=98 \mathrm{kPa}\right)$ of the soils are calculated according to the Japanese Highway Bridge Code (Japanese Road Association, 1997):

$$
G=\frac{\gamma_{\mathrm{t}}}{10 g} V_{\mathrm{SD}}^{2}
$$

where $V_{\mathrm{SD}}$ is the corrected shear wave velocity $(\mathrm{m} / \mathrm{s})$ which itself can be computed using the equation:

$$
V_{\mathrm{SD}}=C_{\mathrm{D}} V_{\mathrm{s}}
$$

where $C_{\mathrm{D}}$ is a correction factor depending on the value of the shear wave velocity. For $V_{\mathrm{s}}<300 \mathrm{~m} / \mathrm{s}, C_{\mathrm{D}}=0.8$ while for $V_{\mathrm{s}} \geq 300 \mathrm{~m} / \mathrm{s}, C_{\mathrm{D}}=1.0$.

The shear wave velocity, $V_{s}$, is obtained from the SPT $N$ value using the method outlined in the Japanese Highway Bridge code (Japanese Road Association, 1997). For sands, with $1 \leq N \leq 50$,

$$
V_{\mathrm{s}}=80 \mathrm{~N}^{1 / 3}
$$

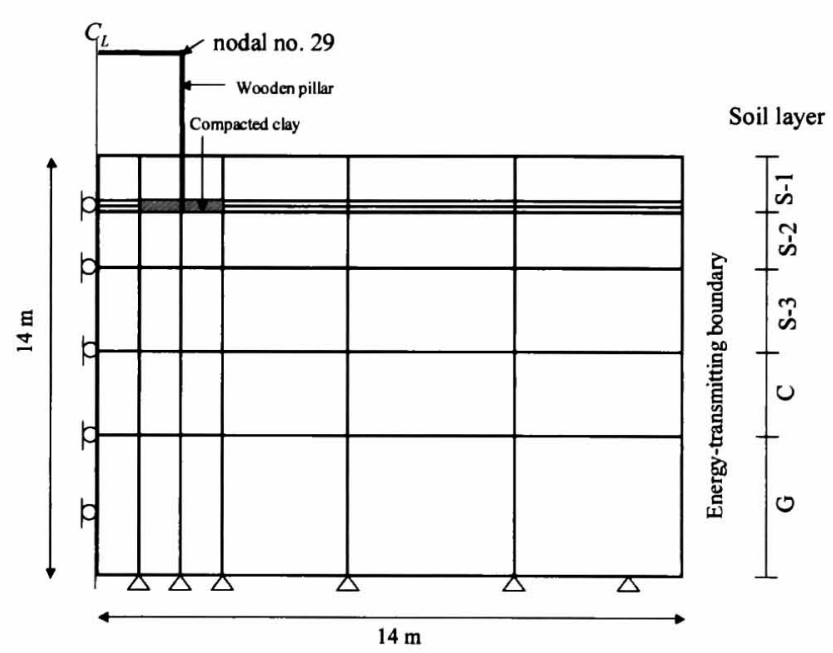

Fig. 13. Earthquake response analysis using program FLUSH

Table 3(b). Input parameters of ground for earthquake response analysis using pogram FLUSH

\begin{tabular}{llcccccccc}
\hline Layer & $\begin{array}{c}\text { Mat } \\
\text { type }\end{array}$ & $\begin{array}{c}\text { Average } \\
\text { SPT } \\
N^{\text {a) }}\end{array}$ & $\begin{array}{c}\text { Shear } \\
\text { wave } \\
\text { velocity } \\
V_{f} \\
(\mathrm{~m} / \mathrm{s})\end{array}$ & $\begin{array}{c}\text { Unit } \\
\text { weight } \\
\left(\mathrm{kN} / \mathrm{m}^{3}\right)^{\mathrm{b})}\end{array}$ & $\begin{array}{c}\text { Poisson's } \\
\text { ratio } \\
v\end{array}$ & $\begin{array}{c}\text { Initial shear } \\
\text { modulus } \\
G_{0} \\
(\mathrm{MPa})\end{array}$ & $\begin{array}{c}\text { Shear } \\
\text { modulus } \\
G\end{array}$ & $\begin{array}{c}G / G_{0} \\
(\mathrm{MPa})\end{array}$ & $\begin{array}{c}\text { Damping } \\
\text { ratio }\end{array}$ \\
\hline S-1 & Sand & 9 & 166 & 17.6 & 0.30 & 49.8 & 31.9 & 0.64 & 0.12 \\
S-2 & Sand & 11 & 178 & 17.6 & 0.30 & 56.8 & 36.3 & 0.64 & 0.12 \\
S-3 & Sand & 10 & 172 & 17.6 & 0.30 & 53.3 & 34.1 & 0.64 & 0.12 \\
C & Clay & 5 & 171 & 16.2 & 0.40 & 48.2 & 30.9 & 0.64 & 0.065 \\
G & Granite & 16 & 202 & 18.6 & 0.30 & 77.2 & 49.4 & 0.64 & 0.12 \\
\hline
\end{tabular}

a) Average SPT $N$ value is determined from Fig. 8 .

b) Average value is determined from Fig. 8 . 


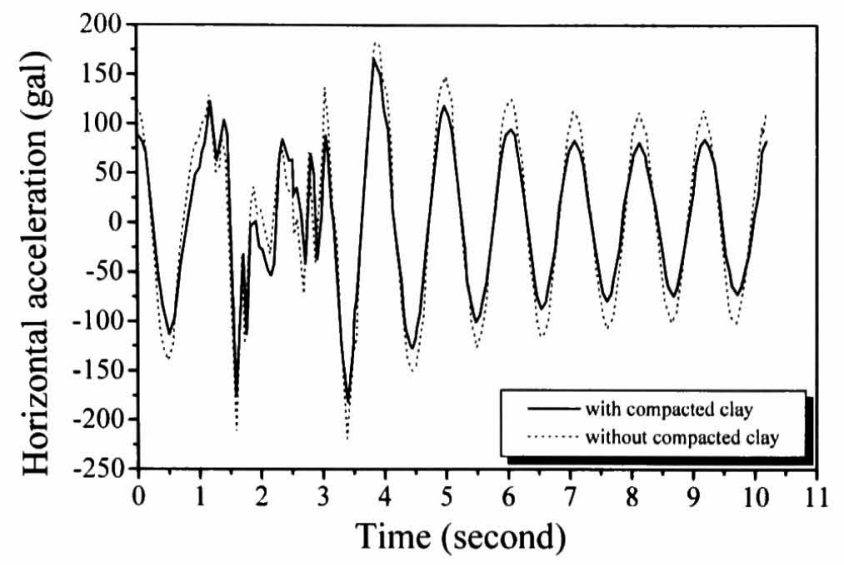

Fig. 14. Results of response analysis of horizontal acceleration versus time for node 29

For the clayey soils, $1 \leq N \leq 25$,

$$
V_{\mathrm{s}}=100 \mathrm{~N}^{1 / 3}
$$

In the above equations, $V_{s}$ is in $\mathrm{m} / \mathrm{s}$.

The damping ratios for S-1, S-2, S-3 and G layers were determined based on the relationship between the normalized shear modulus $\left(G / G_{0}\right)$ and the damping ratio reported by Tatsuoka and Iwasaki (1978). For the C layer which mainly comprises clay, the damping ratio was adopted according to the report on the strain-dependant damping ratio by Kokusho et al. (1982). For simplicity, in this study, it is assumed that the values of $G / G_{0}$ for the ground soils are the same but the shear strain $\gamma$ is different.

In the numerical analysis, the plain strain condition was assumed. The center-line of the superstructure was assumed as the symmetric axis. The modeled range of the ground was $15 \mathrm{~m}$ deep from the ground surface and horizontally $14 \mathrm{~m}$ away from the center-line of the superstructure. In the FLUSH program, the ground was modeled as solid elements with equivalent linear properties. The pillar was modeled as the beam element. The bottom base was adopted as the rigid base. The right boundary was adopted as the energy-transmitting boundary. The displacement boundary conditions at the bottom were adopted as fixed in both horizontal and vertical directions. The displacement boundary condition at the left was adopted as fixed in the horizontal direction but free in the vertical direction. For the semi-symmetry of the considered case, the ground was divided into 42 elements while the super structure was divided into 2 elements.

For seismic loading, the input ground motion was adopted as that of ELCNETRO $1940 \mathrm{~N}-\mathrm{S}$. The recorded maximum acceleration was $320 \mathrm{gal}$ in this wave. The analysis has been carried out for both with and without clay layer to understand the importance of the clay layer. The analysis results for the node 29 are plotted in Fig. 14. From Fig. 14, it is clear that during the observed time period which is about 10 seconds, the calculated acceleration for the node 29 in the case of with stiff clay layer is lower than that in the case of without clay layer. The observed maximum acceleration is $218 \mathrm{gal}$ for the case that the pillar was placed into the ground without the stiff clay layer whereas $181 \mathrm{gal}$ for the case that the pillar was placed above the stiff clay layer. It is clear that from the observed maximum acceleration, $\mathbf{3 7} \mathrm{gal}$ is reduced due to the presence of the clay layer. Yamada (1997) has shown that when the multiple layers of rubber instead of clay layer was placed underlying the wooden pillar, the maximum acceleration for the node 29 would be 141 gal. Compared with the case that the pillar was placed into the ground without stiff clay layer, the maximum calculated acceleration has been reduced by $77 \mathrm{gal}$. The multiple layers of rubber placed between the superstructure and foundation is a well-known modern technique for resisting earthquake. Therefore, it may be concluded that the effect of the clay layer below the pillar on the earthquake-resistance is almost similar to that from the modern techniques.

\section{CONCLUDING REMARKS}

A case study on the historical remains of Mizuki embankment, located in Northern Kyushu, Japan has been presented from the geotechnical engineering point of view. The investigation reveals that the embankment, which was built in $664 \mathrm{AD}$, had steep slope in one direction and there were external moats. Combining with the historical records, it is inferred that the Mizuki embankment was designed and constructed as a defence structure against invasion of the enemy at the ancient time. The steep slope of Mizuki embankment and external moat had played important roles in the defence function.

The investigations of the excavated trench carried out in 1993 have shown that Mizuki embankment was constructed by using the Hanchiku (layer-compaction) method. The investigation further indicated that in the embankment, the sand was compacted in inclined layers dipping to the Dazaifu side. These inclined sand layers might have been provided for draining the seepage water and thereby ensuring the endurance of the embankment against the failure under heavy rainfall conditions. To ensure the stability and probably to shorten the construction period, the loading berm method and a method similar to the modern soil reinforcement technique were adopted. The effects of the loading berm and brushwood reinforcements at the base of the embankment on the stability of the embankment have been brought out by the stability analysis using Fellenius method.

From the investigation on the timber waterspout in the embankment, it has been inferred that the cut and fill technique might have been adopted for installation of timber waterspouts. The soils surrounding the waterspouts had been of rammed earth.

Investigation on the wooden pillar at the west gate of Mizuki embankment revealed that the pillar was placed above the artificially generated stiff clay. Laboratory tests showed that this clay had been overconsolidated with an OCR of 5 to 6 . Numerical analysis using the program 
FLUSH indicated that the pillar-clay system has earthquake-resistant performance, which is very similar to the modern earthquake-resisting technique using the multiple rubber layers.

\section{ACKNOWLEDGMENTS}

The authors appreciate Dr. D. T. Hashiguchi, the officer of Fukuoka Prefecture, for providing opportunities for investigation of the Mizuki remain located in the Dazaifu-shi of Fukuoka Prefecture of Japan. Thanks are also due to Mr. K. Yokota of Kyushu Historical Museum for giving the convenience when the authors performed the survey on the Mizuki remains. Good suggestions and comments from Prof. B. R. S. Murthy, former guest professor of Institute of Lowland Technology, Saga University, are highly appreciated.

\section{NOTATION}

$b_{i}$ : width of slip surface for the $i$ th slice

c: cohesion

$c_{\mathrm{i}}$ : cohesion for the $i$ th slice

$C_{\mathrm{D}}$ : correction factor

E: Young's modulus

$G$ : dynamic shear modulus

$G_{0}:$ initial shear modulus

$l_{i}$ : length of slip surface for the $i$ th slice

$M_{\mathrm{D} 0}$ : sliding moment in the case of without reinforcements

$M_{\mathrm{R} 0}$ : sliding resistance moment in the case of without reinforcements

$M_{\mathrm{DT}}$ : sliding moment in the case of with reinforcements

$M_{\mathrm{RT}}$ : sliding resistance moment in the case of with reinforcements

$N$ : SPT blow count

$R:$ radius of circular sliding arc

$T_{\mathrm{i}}$ : allowable tensile strength of brushwood reinforcement acting on the $i$ th slice

$u_{\mathrm{i}}$ : pore water pressure acting on the $i$ th slice

$v$ : Poisson's ratio

$V_{\mathrm{s}}$ : shear wave velocity

$V_{\mathrm{SD}}$ : corrected shear wave velocity

$W_{\mathrm{i}}$ : weight of $i$ th slice

$\alpha_{i}:$ angle of slip surface for the $i$ th slice

$\gamma_{t}$ : unit weight of soil

$\phi$ : angle of shear resistance

\section{REFERENCES}

1) Brand, E. W. (1984): Landslides in Southeast Asia, A state-of the art report, Proc. 4th Int. Symp. Landslides, Toronto, Canada, 17-59.

2) Dazaifu-shi-Board of Education (1994): Mizuki Remains, Report of 11th-25th Survey-Cultural Assets of Dazaifu-shi, Dazaifu-shi, Japan (in Japanese).

3) Fredlund, D. G. (1987): Slope Stability, John Wiely \& Sons Inc., New York.

4) Fukuoka-ken Board of Education (1976): Mizuki, Excavation Survey Report of 1975 (Showa 50), Fukuoka, Japan (in Japanese).

5) Hayashi, S. (2003): Review on ancient construction technique of historical remains, Geosynthetics Engrg. J., 18, 1-12 (in Japanese).

6) Hayashi, S., Hashiguchi, T. and Yokota (1994): Geotechnical investigation on Mizuki embankment, Proc. 49th Annu. Conf. Jpn. Soc. Civil Engineers, 1, VI247-VI248.

7) Japan Road Association (1996): Code for Highway Bridges, Part V Earthquake Resistant Design, Japanese Geotechnical Society (in Japanese).

8) Kataoka, M. (1996): On the calculation of total amount of earthwork and water storage capacity of moat in the historical remain-Mizuki, Undergraduate Thesis, Saga University, Saga, Japan.

9) Kokusho, T., Yoshida, Y. and Esashi, Y. (1982): Dynamic properties of soft clays for wide strain range, Soils and Foundations, 22(1), 1-18.

10) Kuroita, K. (1915): Report on scientific travel in Fukuoka Prefecture, J. Historiology, 25(3), 577-579 (in Japanese).

11) Kyushu Historical Museum (1997): Dazaifu Historical Remains, Excavation Survey Report of 1996, Fukuoka, Japan (in Japanese).

12) Lysmer, J., Udaka, T., Tsai, C. F. and Seed, H. B. (1975): Flush-A computer program for approximate 3-D analysis of soil structure system, Report EERC 75-30, University of California, Berkeley.

13) Matsumura, K. (1996): The great earthquake which hits the Tsukushi-no-kuni district (a part of the northern Kyushu region) in 679 AD, Museum Kyushu, 54, 76-82 (in Japanese).

14) Motoyama, T. (1995): On the geotechnical properties of Mizuki embankment soils, Undergraduate Thesis, Saga University, Saga, Japan.

15) Nishigaki, M. and Tohari, A. (2000): Laboratory experiments on initiation of rainfall-induced slope failure, Proc. Asian Conf. Unsaturated Soils (eds. by Rahardjo, Toll, and Leong), Balkema, Singapore, 819-824.

16) Ohhama, W. (1974): Materials for Engineering Works, Asakura Pressing, Tokyo, Japan.

17) Rowe, R. K. and Li, A. L. (2002): Geosynthetic-reinforced embankments over soft foundations, Proc. 7th Int. Conf. Geosynthetics (eds. by Delmas and Gourc), Balkema, 5-34.

18) Tatsuoka, F. and Iwasaki, T. (1978): Hysteretic damping of sands under cyclic loading and its relation to shear modulus, Soils and Foundations, 18(1), 25-40.

19) Taylor, D. W. (1937): Stability of earth slopes, J. Boston Soc. Civil Engineers, 24(3), 197-247.

20) Toki, K. (1998): Hydraulic study on restoration of Mizuki embankment, Master Thesis, Saga University, Saga, Japan.

21) Yamada, S. (1997): Geotechnical properties of clays under west gate pillar of Mizuki remain, Undergraduate Thesis, Saga University, Saga, Japan. 